\title{
AN INTRODUCTION TO NATIONAL PROBLEMS IN MEDICAL CARE
}

\author{
I. S. FALK
}

I

It is so much the fashion to write of mankind, nations, democracies or social institutions "at the crossroads" that we tend to become indifferent to the phrase. Yet it is no exaggeration to say that medicine is at a crossroads. Changes in its technology and in its social environment press it irresistibly onward. The traffic at the crossroads is heavy and fast. Medicine cannot stand still. There are many roads ahead. Which shall it follow?

Modern medicine ${ }^{1}$ is not an esoteric art; its foundation is the broad base of modern science. A great profession, endowed with centuries of tradition, is the custodian of a growing body of knowledge. The practice of medicine is now not only an art but also a social institution; as such it is subject to all the influences which affect such institutions, and it is responsive to the changing environment in which it must function. Medicine is not today what it was yesterday nor what it will be tomorrow. The spread of education and the augmented capacities for the conservation of health create enlarged demands for service, so that medicine is increasingly exposed to the pressure of social change.

The role of social factors in affecting health and well-being began to be recognized about two centuries ago when Ramazzini studied occupational diseases. However, the systematic study of social factors in medicine took form only about two generations ago as a specialty of medicine, known as "social medicine." ${ }^{2}$ This development came largely in response to the hygienist's need to understand the influences of conditions of living upon the laborer's health, and the physician's need to answer prob-

* Ph.B., I920; Ph.D., 1923, Yale University. Assistant. Director, Bureau of Research and Statistics, Social Security Board. Member of the (Interdepartmental) Technical Committee on Medical Care. Fellow, American Public Health Association, American Association for the Advancement of Science, American Academy of Political and Social Science, etc. Author of Principles of Vital Statistics (1923); ORganized Medical Service at Fort Benning, Ga. (i932); The Incidence of Illness and the Recetpt and Costs of Medical Care Among Representative Families (with M. C. Klem and N. Sinai) (1933); The Costs of Medical Care (with C. R. Rorem and M. D. Ring) (1933); Security Against Sickness: A Study of Health Insurance (1936). Contributor to professional and lay periodicals.

1 The word "medicine" is used, throughout this article, in its broad sense, to embrace the science and the art of prevention, cure or alleviation of disease. It includes private and public services furnished by physicians, dentists, nurses, hospitals, clinics, public health agencies, etc. At many points, it also includes the functional arrangements through which the technology of medicine operates.

' See, e. g., Sand, Health and Human Progress, An Essay in Sociological Medicine (1935). 
lems of diagnosis and therapy affected by occupation, diet, housing, mental strain and similar factors made important by industrial change and altered habits of living. This new study met relatively little response as a formal discipline in medical education or in medical practice; its techniques were diffuse, so that it lacked appeal to physicians accustomed to deal with the problems of individual patients rather than of statistical groups. It remained a specialty of medicine, instead of becoming a pattern for medical statesmanship. Its objectives have recently been served in some measure by the social teachings of hygiene and public health and by special courses given in a few schools interested in social factors.

The needs out of which social medicine first developed continued to exist and to provide a stimulus for developments in the social sciences. As a result, though social medicine is today almost unknown in medicine, medical sociology is taking definitive form and medical economics is extensively cultivated. Formerly, an inventory of medical facilities dealt with medical practitioners, hospitals, clinics and patients; now such an inventory must include the medical social-work professions, and it is a commonplace to speak of "producers," "consumers," and the problems of "distribution" peculiar to the health services.

There is a current phrase that "change comes to the doctor"; but this expresses only a part truth if it fails to imply that change comes to society and therefore to medicine. Societal adjustments have forceful impacts on the institution which we summarize in the term medicine, on its place in the society which it serves, and on the arrangements through which it operates. Some practitioners, absorbed in their daily tasks and unaware of changing social attitudes among many of their patients, are accustomed to think that they are privileged not only to pursue their profession but also to determine its place and its functional organization in society. It is difficult for them to appreciate that "He that reckons without his host must reckon again."

The plans for the future which now engage our attention must take account of the technology of medicine and the change it is likely to undergo. They must also take account of the social needs and the economic capacities of the people whom this technology is intended to serve.

\section{II}

The socio-economic proposals which confront medicine today can be fully understood only when viewed in their historical perspective. ${ }^{3}$ Such an historical review would go far afield from the present task, but the high points of a few recent developments must be mentioned here.

About twenty years ago, there was an active movement in the United States for the amelioration of economic risks created by sickness. This movement expressed itself in an educational and legislative campaign for social insurance, led by the

\footnotetext{
${ }^{3}$ Sigerist, American Medicine (I934) (translated by Hildegarde Nagel); The Medical Profession and the Public, Am. Acad. of Pol. and Soc. Science (i934); Cabot, The Doctor's Bill (i935); Brown, Physicians and Medicat Care (r937); Riesanan, Medicine in Modern Society (1938); Shryock, Freedom and Interference in Medicine (Nov. 1938) 200 ANwals 32.
} 
American Association for Labor Legislation during the years Igr5-rg20. ${ }^{4} \mathrm{~A}$ demand for enactment of health insurance mirrored and focused the problems of health needs. But public indifference, conflicts with vested interests, opposition of labor and of medical groups, political ineptitudes, and the cross currents of the World War defeated the movement on all fronts.

About ten years ago, the issues again became prominent. Medicine had become more complex. Public education had brought an increasing realization of the benefcent values of modern medical service. Despite the glow of prosperity enjoyed in the nineteen twenties, it was already widely recognized that large proportions of the population cannot purchase the medical care they need. This was a period of great faith in the impelling strength of factual surveys, and a careful study of medicine, its costs, its place in society and the adequacy of its organization was undertaken. The Committee on the Costs of Medical Care-a non-official body including representatives from many interested fields-devoted five years to the task, between I927 and I932. ${ }^{5}$ A large body of information was accumulated. But when the time came to draw conclusions and to look to the future, the Committee divided sharply. There was liberal indulgence in the search for compromises among conflicting interests, but even this did not close the breach between progressive and conservative groups. The conservatism of medical leadership, then and subsequently, frustrated earnest efforts to find rational solutions through voluntary efforts.

About five years ago, the depression crisis brought proposals for social and economic security within the ambit of national legislation. The health program, which at first was of a piece with the programs for old age, public assistance and employment security, crashed on the rocks of organized professional opposition. ${ }^{6}$ But a strong tide of public opinion was already running in, and compromises had to be accepted. The less controversial public health and maternal and child health programs received professional as well as lay endorsement, and were enacted by Congress in the Social Security Act of I935." Thus, while "face" was saved on all sides through these limited enactments, the proposals for health and disability insurance were left to founder.

Last year, the increasing public interest in health needs reached a new height. The relative indifference or inactivity of many groups, and the national scope of the problems, compelled the federal government to take the initiative in formulating a national health program. A long-range plan was developed and sponsored by the President's Interdepartmental Committee to Coordinate Health and Welfare Activities, and it was presented to the public at the suggestion of the President. It received

\footnotetext{
Andrews (editor), Health Insurance, A Positive Statement in Answer to Opponents (IgI7) 7 AM. LABOR LEgIs. REv. No. 4; Chamberlain, Constitutionality of Health Insurance and the Relation of the Social Worker Thereto, Proceedings of Nat. Conf. of Social Work (1917); Williams, The Purchase of Medicai Care Through Fixed Periodic Payment (i932).

- Coma, on Costs of Medical Care, Five-Year Program, Pub. No. I (1928); Falk, Rorem and Ring, The Costs of Medical Care, Pub. No. 27 (I933); Medical Care for the American People: Final Report, Comm. on Costs of Medical Care, Pub. No. 28 (1932).

- Comm. on Economic Security, Report to the Prestient (1935).

${ }^{7} 49$ Stat. 620 (1935), Titles V and VI.
} 
substantial endorsement from representatives of major public groups at the National Health Conference of July 1938, and was transmitted to Congress by the President with a recommendation for careful study. ${ }^{8}$ The bill introduced by Senator Wagner to implement this program, the public hearings by a sub-committee of the Senate Committee on Education and Labor, and the preliminary report of August 4, 1939, to the Senate indicate that the time for action has arrived. ${ }^{\circ}$

\section{III}

It is important, at this time when specific legislative proposals are receiving serious consideration, that efforts should be made to cultivate a clear understanding of the social objectives and the underlying problems in a health program. Social concern with health service and medical care rests not only on humane but also on economic and political grounds. National vigor, social security, and political stability are intimately related to the physical and mental health of the individual. Society has a large stake in measures designed to reduce the incidence of illness or disability and to minimize their sequelae, a stake which is most plainly evident in the costs of dependency caused by illness, disablement or premature death.

Social and economic health measures are directed primarily to the effective organization of health facilities and to the adequate provision of health services. They are only secondarily concerned with the technology of medicine. The content of medicine is the physician's domain. But the circumstances under which he practices and his economic relation to society or to the individual patient are problems of organization, problems in the public domain in which the physician is only one among many who are vitally interested.

When the technoilogy of medicine grew beyond the competence of any individual, specialization became essential. The number and variety of practitioners increased and their coordination became complex. Competition among and within the medical services became acute, and medical costs came into sharp competition with other demands upon the purchasing powers of the public. Through circumstances which no one planned and none foresaw, a profession found itself in a business world. Medicine has been trying to adapt itself to the world about it. The old order of competitive private practice strains itself to conform to social patterns which, in many ways, interfere with the social objectives and the ethical code of an honored profession. The medicine of today cannot afford to drift complacently or without direction into the medicine of tomorrow, unless society is prepared to see the virtues of a profession increasingly supplanted by the dynamics of business.

Social concern is founded on the doctrine that health services are essential and that the individual must be served regardless of his place in society, his individual

${ }^{8}$ Proceedings of the Nat. Health Conf., July 18-20, 1938; Message from the President of the United States Transmitting the Report and Recommendations on National Health Prepared by the Interdepartmental Committee to Coordinate Health and Welfare Activities, F. R. Doc. No. 120, 76th Cong., 1st Sess. (I939).

- National Health Bill, S. 1620, 76th Cong., rst Sess., introduced Feb. 28, 1939; Sen. Comm. on Education and Labor, Preliminary Report on S. I620 ("Establishing a National Health Program"), SEN. Rep. No. I139, 76 th Cong., Ist Sess. (1939). 
capacity to pay for services, or the magnitude of his needs. As a corollary, the practitioner and the institution which is to serve him must be supported, and there is, therefore, inevitably a financial relationship in which society, as well as, physician and patient, is concerned. The economic problems which arise cannot be defined solely in terms of consumer needs or demands, production costs, and price policies. Other elements complicate any purely economic approach to the economic problems of medicine. There are ideals and humane considerations and elements of social prestige to be taken into account; and many attributes of a professional service are to be distinguished from the characteristics of a trade relation.

Medicine and the society which it serves must preserve a careful balance between professional controls in the provision of medical care and economic interests in the method of paying for it. Neither the one nor the other may be permitted to dominate.

Long ago the professional code dictated that the patient shall seek out the physician. The social doctrine now dictates that the patient's need shall be met. These are not incompatible, but their simultaneous application is not always practical without adjustments in the functional organization of medicine. The professional code holds fast to the principle of free choice of physician by the patient, not merely because it is an ancient maxim but because it is a safeguard of the patient's confidence and trust in his physician. Yet the principle comes into conflict with another maxim, long known to every student of social philosophy, calling for restriction of personal choice when "the consumer is not a proper judge of the quality of the ware."10 Every proposal for new arrangements under which medicine shall serve the public need must take into account that in medicine, more than in almost any other field, the patient is deficient in knowledge and competence to judge his need, his purchase, or the fair price. Moreover, it is only confusing to focus on the principle of free choice while being myopic to the fact that, in many circumstances, the principle is already little practiced or observed. This is especially true in clinic and in subsidized hospital services, in communities where professional personnel is limited in number or variety, and in the diverse circumstances where the charges for service and the lack of public information limit free choice.

Nor is the physician-the hypothetical seller of a service in a free marketaltogether analogous to the producer in our industrial exchange. $\mathrm{He}$ is probably closer to the public utility in which society, by reason of an imminent interest, vests a monopoly subject to limitations and restraints. Society determines who may hold himself out as a physician and, in return for his exclusive licensure, exacts from him the price of his professional code. It gives him special privileges in the services he may furnish and sell; but his code requires that he shall serve all who seek him out, without regard for their ability to pay. Social judgments and judicial pronouncements generally agree that he is entitled to a fee according to the patient's ability to pay-little or nothing from the poor, and in proportion to their means from the rich.

The sliding fee scale once served as a useful instrument whereby the physician

${ }^{10}$ Hamilton, Personal Statement in Medical Care for the American People: Final Report, Comm. on Costs of Mídical Care, Pub. No. 28 (1932) p. I93. 
adjusted his charge to the means of his patients and, in the net, earned his competence. In the complex urban and industrial world of today the practice cannot be so simple. The physician who serves the poor may be one who also serves the rich, or he may not. The burdens of free care are frequently too heavy for many practitioners. The public interest and, in turn, the public purse already intervene to meet the cost of services which might once have been the gratuity of the physician. Though public medical expenditures are already large, they are grossly inadequate and the public purse must increasingly intervene. But, obviously, when society provides financial support for services furnished to the poor, and relieves the physician of some of the burdens of free care, it deprives him, in equal measure, of his economic defense for the practice of adjusting upwards his charges to the well-to-do. Also, it transfers to a public officer the responsibility, formerly exercised by the physician, of determining that a patient is destitute and entitled to service without a direct charge.

A society which accepts broad responsíbility for dependency and destitution must also make adequate provision for health services. Here financial arguments reinforce humane considerations. Society cannot afford to have prevention neglected or sickness unattended; it cannot afford to support the needy halt, blind, widowed, and orphaned whose dependency can be prevented through services that are available and relatively inexpensive. Inadequacies in the receipt of health service are luxuries which we cannot afford.

\section{IV}

Proposals to extend and improve health services must be tested by the characteristics of existing deficiencies. The remedy must fit the need. A large volume of illness and disability occurs, year after year, from causes we know how to control; preventive services should be strengthened and expanded. An enormous volume of illness and disability is unattended, or is attended inadequately or too late in the course of the disease; remedial services should be made more generally available. Large numbers of people are without the means necessary, under prevailing arrangements, for the purchase of the services they need; they should be assisted to obtain these services within their means and under conditions which preserve dignity and self-respect. There are millions of people living in communities which are deficient in personnel and facilities essential for the furnishing of modern service; these deficiencies should be made good. There are millions who are inadequately educated in hygiene and the opportunities offered by modern medicine; health education should be expanded to equip them with the knowledge and understanding essential for the effective utilization of the health services. In each of these illustrations, and in many more of equal importance that could be cited, the need is rooted in social and economic problems and the remedy involves socio-economic adjustments.

An analysis of the underlying problems ${ }^{11}$ is, in a sense, comparatively simple be-

${ }^{21}$ Falk, Rorem and Ring, The Costs of Medical Care, Pub. No. 27 (1933); Falk, Security Against Sickness: A Study of Health Insurance (1936); Cabot, The Doctor's Bill (i935); Mizlis, Sickness and Insurance (i937); Reed, Health Insurance (1937); AMA Bureau of Med. Econ., Factual Data on Medrcal Economics (1939); Perrott, Tibbits, and Britten, The National Health Survey: 
cause there is one fundamental and causal problem to which most others are secondary or related. This primary problem arises from a basic characteristic of the incidence of illness and the variations in services and costs that are involved. Though the amount of illness which will occur in a population of any considerable size can be forecast with substantial accuracy, the individual cannot foresee the experience which he himself is likely to face. Illness strikes the individual in an unpredictable and uncertain manner. One person may go through a year of life or even many years with little or no illness of serious duration or severity; another may be stricken frequently and catastrophically.

The costs of illness or medical need are highly variable in their impacts upon family budgets and security. Small costs for medical care may be absorbed in a family budget which is above the bare subsistence level; but the occurrence of a "high cost" illness, even when moderate fees are charged for each unit of service, may be a financial catastrophe for a family of small, modest, or even substantial means.

Illness and disability are not considerate of the family exchequer, and large costs may fall upon small purses. The plain fact, well attested by numerous studies, is that families cannot, even if they would, budget against expenditures which come unexpectedly and which fluctuate within such broad ranges that they may exceed even annual income, and at the same time destroy earning power. ${ }^{12}$

Nor do the statistics of actual family expenditures tell the whole story. Knowing in advance that they cannot pay large medical bills, many families ask for "free" care, and many more go without medical attention which they know they need. Nor can anyone be unaware of the distress in those families which incur large bills and undertake to pay them. In one case or another, the savings of a lifetime may be wiped out, the hopes and dreams for a home or farm thwarted, educational opportunities sacrificed, the family deprived of the amenities of life. The burdens are equally great whether the result is unmet need or financial strain.

The main problem is concealed when the costs of sickness are examined in terms of average incidence or average charges. Proof that families could meet the average costs would have significance only if families were permitted or enabled to meet their obligations by paying the average costs. This is precisely the reason why many investigations have led to the conclusion that medical costs can be met by people, in

Scope and Method of the Nation-Wide Canvass of Sickness in Relation to Its Social and Economic Setting, Public Health Reports (Sept. 1939); Perrott, The State of the Nation's Health (Nov. I936) I88 AnNars 131; Perrott and Holland, Health as an Element in Social Sectrity (March, I939) 202 ANNaLs II6.

${ }_{12}$ Falk, Klem, and Sinat, The Incidence of Illness and the Rfceipt and Costs of Medical Care Among Representative Family Groups, Pub. No. 26 (1933); Klem, Medical Care and Costs in California Families in Relation to Economic Status (1935); Dodd and Penrose, Economic Aspects of Medicaz Services: With Special Reference to Conditions in California (1939); Wilson and Metzler, Sickness and Medical Care in an Ozark Area in Arkansas, Univ. OF ARK. Bull. No. 353 (1938); Krumlein, The Rural Health Situation in South Dakota, SoUth Dakota StATE Coli. OF AGr. AND MECH. ARTs, Buli. No. 258 (193r); Wheeler, Impairments in a Rural Population, The Milbank Memorial Fund Quarterly (July and Oct., I937, Jan. and April, I938); Klem, Family Outlay for Hospital Care (Feb. I939) 52 Modern Hospital 45; Klem, Family Expenditures for Medical and Dental Care (1939) 26 Journal of the Am. Dental Ass'n "828; Klem, Who Purchase Private Duty Nursing Services? (1939) 39 Aar. Journal of NuRsing 1069. 
their respective stations in life and within their individual budgets, only if these costs are distributed among groups of people and over periods of time. This is equivalent to saying that the burdens of medical costs could be mitigated if the principle of insurance were applied.

Instalment payment should not be confused with insurance. Instalment payment distributes costs over time, but it does not distribute the primary risk among groups of people. Instalment payment of medical costs does not insure an individual or family against a future risk of medical bills; it only mortgages future earnings to pay for a catastrophe which has already occurred.

It is recognized, of course, that neither insurance nor any other budgeting device will solve the problem of those who have no means. For them, medical services-like food, clothing and shelter-must be provided, presumably at public expense.

Variations and uncertainties in sickness costs have their counterpart in variations and uncertainties in professional and institutional incomes. Sharp curtailment of income during the depression led many physicians to look with favor on the stabilized income of salaried practice and of service for insurance groups, and to demand tax support for services to the indigent-even though such tax funds were formerly viewed with grave suspicion as an entering wedge for state medicine.

The burden of costs for the "consumer" and the hazards of income for the "producer" are inextricably enmeshed with the economic resources of the community. Inadequacies in the incomes of individuals, groups and communities are reflected in variation in the ability to support medical practitioners and institutions. Usually those who are least able to meet medical costs are not only least able to support medical facilities but are also members of groups and communities which are least equipped with such facilities. This is all the more serious because, in general, those in the poorest economic circumstances have the highest sickness and disability rates, need the largest volumes of service and the most extensive personnel and facilities.

Intimately related to the economic problems of medical care are the corresponding problems concerned with disablement and disability wage-loss. The underlying problem here is quite like that which is created by the variations and uncertainties of individual medical costs. The average amount of disability which may occur among gainfully employed persons and the average loss of earnings would raise no grave issues if each had to bear only the average amount. But, in general, the individual worker can no more know in advance whether he will suffer little or much disability, or will become permanently disabled, than he can foretell how much sickness will befall him or his family or what the costs will be. Disablement of the mother and housewife may be tragic for the family; but disablement of the breadwinner brings catastrophe.

Among those who cannot accumulate substantial financial reserves-and this includes an overwhelming majority of the population-the fear of disability hangs like a sword of. Damocles over the financial independence and the security of the family. It is therefore not surprising that nearly every large system of health insur- 
ance furnishes both sickness services and wage-loss benefits, and that all but two of the large nations which have developed old age insurance (Spain and the United States) have provided protection against permanent retirement due to invalidity. Several countries have both sickness and invalidity insurance, or the latter only, though they do not have old age insurance. The assurance of health security involves not only prevention of disease but also protection against both the costs and the losses which illness brings in its wake.

A health program for our country starts with a vast equipment: more than a million professional practitioners of all kinds (physicians, dentists, nurses, and technicians) and lay and semi-technical employees; approximately six thousand hospitals and special institutions, with more than a million beds; unexcelled schools for professional education and training; thousands or tens of thousands of clinics, health centers and institutions for public education and guidance; a network of health and welfare agencies at all levels of government-federal, state, and local; voluntary agencies which reach into almost every community, including national, regional and local organizations of civic, fraternal, religious, charitable and other associations familiar with health needs and devoted to the provision of health services. This vast armamentarium is available; its personnel is ready and eager for more extensive and more effective organization of public service. But neither such readiness nor such eagerness is sufficient to resolve practical difficulties or to avoid conflicts in aims and activities.

A new health program for the nation must strengthen and expand the preventive services; on this there is general agreement, but there are differences of opinion as to the extent to which these services should be performed as a public or as a private enterprise.

Special provisions must be made to safeguard maternity, infancy and childhood; on this there is little difference of opinion, but there are complex problems of relationship with the general health services and with private practices.

Inadequacies in hospital, clinic, health center and related facilities must be met; on this there is strong public support, but it divides into factions on secondary questions concerning the sources of funds, the location of new institutions, and the protection of existing facilities against competition from new ones.

Medical care must be furnished to the needy poor; on this public opinion reinforces professional demand, but there are deep cleavages as to the administrative mechanisms to be used, the basis of payments to practitioners, the allocation of responsibilities among official and non-official agencies, and the relative financial responsibilities of local, state and national governments.

Medical care must be made available to people of small means under arrangements which avoid the burdens of variable and uncertain costs, safeguard quality, and assure support to professional personnel and facilities; on this there is wide 
agreement in principle, but there are also sharp differences of opinion, both rational and emotional, which revolve around the functional organizations that should be developed, and some of these differences center as much on such calorific words and phrases as regimentation, socialized medicine, state medicine, public medicine, health insurance, un-American activities, as on specific proposals.

Wage-earners and salaried workers must have protection against wage loss during periods of temporary or permanent disability; on this there is no important difference of opinion, but there remains yet to be reached full agreement as to inter-relations with medical care provisions, workmen's compensation, unemployment compensation, and old age and survivors insurance at state and federal levels of operation.

The objectives and the broad outlines of a national health program are only little in dispute, but the details and the specific contents present many issues. Within the boundaries of the program there are problems which raise profound questions concerning public and private relationships, the role of government in discharging public responsibilities, the expansion of public services at the expense of private domains. There are issues as to public support of professional education, and as to public and professional responsibilities for the quality of service subsidized or financed by public funds. There are large stakes concerned with preservation of vested interests. In short, there are the manifold complexities involved in the reordering of a social institution which vitally affects the life and welfare of every member of our society. A health program built on existing facilities must of necessity contain many compromise plans and provisions. It must embody internal devices for concurrent evaluation of its practices, for adjustment, and for change and improvement. Discussion and understanding are essential now that legislative action is impending.

The magnitude and the complexity of a national health program are great. The parts require careful coordination, and the whole needs to be seen in broad perspective. The objectives deserve thorough understanding. Yet understanding alone will avail little if, in the face of needs which are widespread and acute, study and contemplation continue to remain an alternative for action. There are many aspects of the program which no one can now wholly grasp, and there are many questions which no one can confidently answer. But among these the largest number are those which only experience can resolve, and no amount of cloistered study or factional dispute can serve as a substitute. The most costly experience is that which arises from inaction in the face of technological change and social need. 